\title{
PENGARUH KOMPETENSI PEGAWAI, ETOS KERJA, FASILITAS KERJA DAN DISIPLIN KERJA TERHADAP PENGEMBANGAN PEGAWAI DI KANTOR WILAYAH DJP SUMATERA UTARA I
}

\author{
Muhammad Arkan Sahadat \\ Universitas Islam Sumatera Utara \\ mhd.adkansahadat@gmail.com
}

\begin{abstract}
The formulation of the problem in this study are: Does Employee competence affect employee development in the North Sumatra I DGT Regional Office. Does work ethic affect employee development? Does work facilities affect employee development. Does work discipline affect employee development? Does employee competence, work ethic, work facilities and discipline simultaneously have a significant effect on employee development, Research Objectives Are: The data analysis technique used is multiple linear regression analysis. The results showed that there was a significant influence between competencies on employee development, because according to the results of the analysis of $t$ count $>t$-table $(2.753>1.67)$ at $n=56$ with a significance level of $95 \%$. There was a significant influence between work ethic on development employee, the results of analysis of arithmetic $>t$-table $(2.114>1.67)$ at $n=56$ with a significance level of $95 \%$. There is a significant influence between work facilities on employee development, because according to the results of analysis of arithmetic > t-table $(1,722>1.67)$ at $n=56$ with a significance level of $95 \%$. There is a significant influence between work Discipline on employee development, because according to the results of $t$ analysis $>t$-table $(2.664>1.67)$ at $n=56$ with a significance level of 95\%. F-count value> F table (103,996> 2, 56) together (multiple) there is a positive and significant influence of employee competence, work ethic, work facilities and work discipline on employee development. Thus the hypothesis proposed is accepted.
\end{abstract}

Keyword: Employee competence, work ethic, work facilities, work discipline and employee development.

\begin{abstract}
ABSTRAK : Rumusan masalah dalam penelitian ini adalah : Apakah kompetensi Pegawai berpengaruh terhadap pengembangan pegawai di Kantor Wilayah DJP Sumatera Utara I?. Apakah etos kerja berpengaruh terhadap pengembangan pegawai?, Apakah fasilitas kerja berpengaruh terhadap pengembangan pegawai?, Apakah disiplin kerja berpengaruh terhadap pengembangan pegawai?, Apakah kompetensi pegawai, etos kerja, fasilitas kerja dan disiplin secara bersamaan berpengaruh signifikan terhadap pengembangan pegawai?, Tujuan Penelitiaan Adalah : Teknik analisis data yang digunakan adalah analisis Regresi Linier berganda. Hasil penelitian diperoleh bahwa Ada pengaruh yang signifikan antara kompetensi terhadap pengembangan pegawai, karena menurut hasil analisis thitung $>t$-tabel $(2,753>1,67)$ pada $n=$ 56 dengan taraf signifikansi 95\%.Ada pengaruh yang signifikan antara etos kerja terhadap pengembangan pegawai, hasil analisis thitung $>t$-tabel $(2,114>1,67)$ pada $n=56$ dengan taraf signifikansi 95\%.Ada pengaruh yang signifikan antara Fasilitas kerja terhadap pengembangan pegawai, karena menurut hasil analisis thitung $>t$-tabel $(1,722>1,67)$ pada $n=56$ dengan taraf signifikan 95\%. Ada pengaruh yang signifikan antara Disiplin kerja terhadap pengembangan pegawai, karena menurut hasil analisis $t$ hitung $>t$-tabel $(2,664>1,67)$ pada $n=56$ dengan taraf signifikan 95\%.Nilai F-hitung $>F$ tabel $(103,996>2,56)$ secara bersama-sama (multiple) terdapat pengaruh positif dan signifikan kompetensi pegawai, etos kerja, Fasilitas kerja dan disiplin kerja terhadap pengembangan pegawai. Dengan demikian hipotesis yang diajukan diterima kebenarannya.
\end{abstract}

Keyworld: Kompetensi pegawai, etos kerja, fasilitas kerja, disiplin kerja dan pengembangan pegawai. 


\section{Pendahuluan}

Produktivitas pegawai dalam suatu organisasi masing-masing berbeda dan tergantung dari kemampuan serta keterampilan dan kebutuhan pegawai itu sendiri dan adanya pengembangan pegawai sesuai perkembangan zaman dan ilmu teknologi. Untuk pengembangan pegawai tidak terlepas juga dari lamanya ia bekerja dan bagaimana ia dalam penyelesaian kerjanya serta kemampuan pegawai itu sendiri. Pengembangan Pegawai sangat penting agar tercipta sumber daya manusia yang memiliki semangat kerja dan keterampilan yang tinggi. Dengan melakukan pengembangan pegawai diharapkan agar pegawai dapat melaksanakan aktivitas kerja secara fisik yang diarahkan oleh pimpinan dengan memberikan perintah, memperbaiki hasil kerja mereka serta untuk menimbulkan rasa percaya diri dalam melakukan kreativitas kerja mereka.

Pegawai yang telah memiliki kualitas kerja serta memiliki kemauan dan tanggung jawab terhadap pekerjaan akan terdorong untuk memiliki kesempatan lebih maju Salah satu juga dorongan seseorang bekerja pada suatu organisasi atau perusahaan adalah adanya kesempatan untuk maju yakni adanya kesempatan untuk mengembangkan diri karena hal ini merupakan suatu kebutuhan manusia. Sudah menjadi sifat dasar dari manusia pada umumnya untuk menjadi lebih baik, lebih maju dari posisi yang dipunyai pada saat ini, karena itulah mereka menginginkan suatu kemajuan dalam hidupnya. Kemauan untuk maju di dalam organisasi sering disebut sebagai promosi dan promosi adalah salah satu upaya pengembangan sumber daya manusia. Dengan demikian seiring dengan adanya kemauan pegawai untuk maju atau mengembangkan diri maka tidak lepas dari peran pimpinan organisasi dalam upaya pengembangan pegawai. Karena pengembangan pegawai yang hanya tergantung dari usaha dari pegawai secara individual tidak sesuai dengan kepentingan organisasi. Oleh sebab itu perlu dukungan dari pimpinan baik pimpinan personalia maupun pimpinan organisasi sehubungan dengan aplikasi manajemen. Pimpinan sangat berperan penting dalam pengembangan pegawai, mulai dari program perencanaan, latihan dan pengembangan karir, dukungan manajemen, Akan tetapi juga tidak lepas dari pada kepemimpinan yang dilaksanakan dalam organisasi tersebut.
Pengembangaan pegawai di Kantor Wilayah DJP Sumatera Utara I masih kurang. Hal ini disebabkan karena pengaruh beberapa faktor seperti kompetensi, komunikasi, lingkungan kerja dan etos kerja pegawai. Semangat kerja pegawai yang tinggi juga dipengaruhi kompetensi, Kompetensi pegawai yakni pengetahuan, keterampilan dan kemampuan atau kapabilitas yang dimiliki oleh seorang pegawai yang telah menjadi bagian dari dirinya sehingga mewarnai perilakunya dalam melaksanakan tugas yang diembannya. Selanjutnya kompetensi merupakan salah satu yang perlu diperhatikan. Fenomena yang ada berkaitan dengan kompetensi di Kantor Wilayah DJP Sumatera Utara I adalah pegawai yang masih belum memuaskan sehingga pegawai kurang terampil dalam melaksanakan tugas, belum mampu sepenuhnya melayani publik dengan baik Karena dengan kompetensi pegawai yaitu sikap dan kemampuan dari pegawai itu untuk dapat melaksanakan tugas yang diberikan dan kesanggupan menghadapi masalah yang dihadapi dalam organisasi, Kompetensi pegawai penting agar mampu untuk mencapai misi, nilai dan tujuan organisasi, kompetensi pegawai mempengaruhi kinerja pegawai. Kompetensi pegawai yang dimaksud adalah pengetahuan, keterampilan dan kemampuan atau kapabilitas yang dimiliki oleh seorang pegawai yang telah menjadi bagian dari dirinya sehingga mewarnai perilakunya dalam melaksanakan tugas yang diembannya.

Disamping itu pegawai harus memiliki etos kerja yang tinggi karena etos kerja meliputi : efesiensi, tepat waktu, kejujuran, kesadaran untuk berubah, rasional dalam pengambilan keputusan, energik, kerjasama serta berorientasi ke masa depan, etos kerja akan mewarnai tingkah laku kita dalam bekerja dan akan berusaha tampil baik pada saat menjalankan peran masing-masing. Sewaktu menjalankan peran masing-masing, etos kerja seseorang akan dapat diketahui dengan berdasarkan ciri-ciri tertentu dan dengan etos kerja pegawai memberi gaambaran kepada pimpinan apakah seorang pegawai tersebut perlu dilakukan pengembangan atau tidak.

Selanjutnya fasilitas kerja merupakan kondisi yang bersangkutan pada saat tempat kerja dibentuk perusahaan. Sejalan dengan pendirian perusahaan, manajemen perusahaan selayaknya mempertimbangkan fasilitas kerja bagi pegawai. Perencanaan lingkungan kerja berarti 
menentukan susunan semua komponen fisik maupun non fisik yang mendukung aktivitas kerja pegawai. Pimpinan harus memperhatikan fasilitas kerja apakah pegawai mampu menggunakan fasilitas kerja yang ada atau tidak atau apakah pegawai perlu dilakukan pengembangan.

Disiplin pegawai sangat penting dalam organisasi, tanpa ada disiplin semua program yang telah direncanakan akan tidak berguna dan tanpa disiplin pegawai perencanaan organisasi tidak akan tercapai. Oleh sebab itu para pegawai harus memiliki disiplin kerja sehingga dengan disiplin kerja semua program yang telah direncanakan akan dapat dicapai dan dengan disiplin semu kegiatan akan dapat diselesaikan.

Kurangnya kompetensi pegawai, rendahnya etos kerja, kurangnya fasilitas yang tidak mendukung terhadap kerja pegawai dan disiplin pegawai masih adanya tidak disiplin ditambah lagi pengembangan pegawai juga belum maksimal atau masih rendah, rendahnya beberapa faktor tersebut menyebabkan pengembangan pegawai tidak seperti yang diharapkan.

Adapun Tujuan penelitian adalah

1. Untuk mengetahui pengaruh kompetensi pegawai terhadap pengembangan pegawai

2. Untuk mengetahui pengaruh etos kerja terhadap pengembangan pegawai

3. Untuk mengetahui pengaruh fasilitas kerja terhadap pengembangan pegawai

4. Untuk mengetahui pengaruh disiplin terhadap pengembangan pegawai

5. Untuk mengetahui pengaruh kompetensi pegawai, etos kerja, fasilitas kerja dan disiplin secara simultan terhadap pengembangan pegawai

\section{Metode Penelitian \\ 2.1. Populasi dan Sampel}

Sugiyono (2010: 90) mengemukakan: "Populasi adalah wilayah generalisasi yang terdiri atas objek/subjek yang mempunyai kualitas dan karakteritik tertentu yang ditetapkan oleh peneliti. Berdasarkan pengertian ini populasi bisa berupa semua individu yang mewakili pola kelakuan tertentu atau sebahagian dari kelompok itu ". Artinya populasi dapat berupa individu yang mewakili pola kelakuan atau sebagian. Populasi penelitian ini adalah semua pegawai di Kantor Wilayah DJP Sumatera Utara I yang berjumlah Populasi penelitian ini adalah semua pegawai di Kantor Wilayah DJP Sumatera Utara I berjumlah 126 orang.

Sampel penelitian ditetapkan berdasarkan ketentuan Arikunto, (2010:120) yaitu :"apabila populasi kurang dari 100 orang, lebih baik diambil semua sehingga penelitian merupakan penelitian populasi. Jika jumlah subjeknya lebih dari 100 orang, dapat diambil $10-15 \%$ atau 20 - $25 \%$ atau lebih." Disebabkan populasi lebih 100 orang maka sampel penelitian ditetapkan sebesar $45 \%$ (57 orang)

\subsection{Pengujian Validitas}

Uji validitas dilakukan terhadap isi dari suatu instrumen, tujuan dilakukannya pengujian ini adalah untuk mengukur ketetapan instrumen yang digunakan. Untuk pengujian validitas ini dilakukan dengan menggunakan koefisien korelasi Product Moment. Item kuesioner dikatakan valid apabila nilai $r_{\text {hitung }}>r_{\text {tabel }}$. Uji validitas pada penelitian ini dapat dilihat pada table berikut :

Table 1

Uji Validitas variable $\mathrm{X}_{1}$

\begin{tabular}{|c|c|c|c|c|}
\hline Pertanyaan & $\begin{array}{c}\text { Nilai Korelasi } \\
(\mathbf{r})\end{array}$ & r-tabel & Keterangan & Kesimpulan \\
\hline 1 & 0.637 & 0,361 & $\mathrm{r}_{\text {hitung }}>\mathrm{r}_{\text {tabel }}$ & Valid \\
\hline 2 & 0.413 & 0,361 & $\mathrm{r}_{\text {hitung }}>\mathrm{r}_{\text {tabel }}$ & Valid \\
\hline 3 & 0.610 & 0,361 & $\mathrm{r}_{\text {hitung }}>\mathrm{r}_{\text {tabel }}$ & Valid \\
\hline 4 & 0.724 & 0,361 & $\mathrm{r}_{\text {hitung }}>\mathrm{r}_{\text {tabel }}$ & Valid \\
\hline 5 & 0.687 & 0,361 & $\mathrm{r}_{\text {hitung }}>\mathrm{r}_{\text {tabel }}$ & Valid \\
\hline 6 & 0.717 & 0,361 & $\mathrm{r}_{\text {hitung }}>\mathrm{r}_{\text {tabel }}$ & Valid \\
\hline 7 & 0.655 & 0,361 & $\mathrm{r}_{\text {hitung }}>\mathrm{r}_{\text {tabel }}$ & Valid \\
\hline 8 & 0.477 & 0,361 & $\mathrm{r}_{\text {hitung }}>\mathrm{r}_{\text {tabel }}$ & Valid \\
\hline 9 & 0.763 & 0,361 & $\mathrm{r}_{\text {hitung }}>\mathrm{r}_{\text {tabel }}$ & Valid \\
\hline 10 & 0.503 & 0,361 & $\mathrm{r}_{\text {hitung }}>\mathrm{r}_{\text {tabel }}$ & Valid \\
\hline
\end{tabular}

Sumber : Hasil pengolahan Data, 2019 
Table 2

Uji Validitas variable $\mathrm{X}_{2}$

\begin{tabular}{|c|c|c|c|c|}
\hline Pertanyaan & $\begin{array}{c}\text { Nilai Korelasi } \\
(\mathbf{r})\end{array}$ & r-tabel & Keterangan & Kesimpulan \\
\hline 1 & 0.720 & 0,361 & $\mathrm{r}_{\text {hitung }}>\mathrm{r}_{\text {tabel }}$ & Valid \\
\hline 2 & 0.745 & 0,361 & $\mathrm{r}_{\text {hitung }}>\mathrm{r}_{\text {tabel }}$ & Valid \\
\hline 3 & 0.535 & 0,361 & $\mathrm{r}_{\text {hitung }}>\mathrm{r}_{\text {tabel }}$ & Valid \\
\hline 4 & 0.632 & 0,361 & $\mathrm{r}_{\text {hitung }}>\mathrm{r}_{\text {tabel }}$ & Valid \\
\hline 5 & 0.438 & 0,361 & $\mathrm{r}_{\text {hitung }}>\mathrm{r}_{\text {tabel }}$ & Valid \\
\hline 6 & 0.680 & 0,361 & $\mathrm{r}_{\text {hitung }}>\mathrm{r}_{\text {tabel }}$ & Valid \\
\hline 7 & 0.419 & 0,361 & $\mathrm{r}_{\text {hitung }}>\mathrm{r}_{\text {tabel }}$ & Valid \\
\hline 8 & 0.572 & 0,361 & $\mathrm{r}_{\text {hitung }}>\mathrm{r}_{\text {tabel }}$ & Valid \\
\hline 9 & 0.688 & 0,361 & $\mathrm{r}_{\text {hitung }}>\mathrm{r}_{\text {tabel }}$ & Valid \\
\hline 10 & 0.713 & 0,361 & $\mathrm{r}_{\text {hitung }}>\mathrm{r}_{\text {tabel }}$ & Valid \\
\hline
\end{tabular}

Sumber : Hasil pengolahan Data, 2019 Table 3

Uji Validitas variable $\mathrm{X}_{3}$

\begin{tabular}{|c|c|c|c|c|}
\hline Pertanyaan & $\begin{array}{c}\text { Nilai Korelasi } \\
(\mathbf{r})\end{array}$ & r-tabel & Keterangan & Kesimpulan \\
\hline 1 & 0.586 & 0,361 & $\mathrm{r}_{\text {hitung }}>\mathrm{r}_{\text {tabel }}$ & Valid \\
\hline 2 & 0.517 & 0,361 & $\mathrm{r}_{\text {hitung }}>\mathrm{r}_{\text {tabel }}$ & Valid \\
\hline 3 & 0.722 & 0,361 & $\mathrm{r}_{\text {hitung }}>\mathrm{r}_{\text {tabel }}$ & Valid \\
\hline 4 & 0.799 & 0,361 & $\mathrm{r}_{\text {hitung }}>\mathrm{r}_{\text {tabel }}$ & Valid \\
\hline 5 & 0.737 & 0,361 & $\mathrm{r}_{\text {hitung }}>\mathrm{r}_{\text {tabel }}$ & Valid \\
\hline 6 & 0.677 & 0,361 & $\mathrm{r}_{\text {hitung }}>\mathrm{r}_{\text {tabel }}$ & Valid \\
\hline 7 & 0.696 & 0,361 & $\mathrm{r}_{\text {hitung }}>\mathrm{r}_{\text {tabel }}$ & Valid \\
\hline 8 & 0.584 & 0,361 & $\mathrm{r}_{\text {hitung }}>\mathrm{r}_{\text {tabel }}$ & Valid \\
\hline 9 & 0.456 & 0,361 & $\mathrm{r}_{\text {hitung }}>\mathrm{r}_{\text {tabel }}$ & Valid \\
\hline 10 & 0.430 & 0,361 & $\mathrm{r}_{\text {hitung }}>\mathrm{r}_{\text {tabel }}$ & Valid \\
\hline
\end{tabular}

Sumber : Hasil pengolahan Data, 2019

Table 4

Uji Validitas variable $\mathrm{X}_{4}$

\begin{tabular}{|c|c|c|c|c|}
\hline Pertanyaan & $\begin{array}{c}\text { Nilai Korelasi } \\
(\mathbf{r})\end{array}$ & r-tabel & Keterangan & Kesimpulan \\
\hline 1 & 0,610 & 0,361 & $\mathrm{r}_{\text {hitung }}>\mathrm{r}_{\text {tabel }}$ & Valid \\
\hline 2 & 0,403 & 0,361 & $\mathrm{r}_{\text {hitung }}>\mathrm{r}_{\text {tabel }}$ & Valid \\
\hline 3 & 0,693 & 0,361 & $\mathrm{r}_{\text {hitung }}>\mathrm{r}_{\text {tabel }}$ & Valid \\
\hline 4 & 0,604 & 0,361 & $\mathrm{r}_{\text {hitung }}>\mathrm{r}_{\text {tabel }}$ & Valid \\
\hline 5 & 0,632 & 0,361 & $\mathrm{r}_{\text {hitung }}>\mathrm{r}_{\text {tabel }}$ & Valid \\
\hline 6 & 0,568 & 0,361 & $\mathrm{r}_{\text {hitung }}>\mathrm{r}_{\text {tabel }}$ & Valid \\
\hline 7 & 0,625 & 0,361 & $\mathrm{r}_{\text {hitung }}>\mathrm{r}_{\text {tabel }}$ & Valid \\
\hline 8 & 0,725 & 0,361 & $\mathrm{r}_{\text {hitung }}>\mathrm{r}_{\text {tabel }}$ & Valid \\
\hline 9 & 0,366 & 0,361 & $\mathrm{r}_{\text {hitung }}>\mathrm{r}_{\text {tabel }}$ & Valid \\
\hline 10 & 0,636 & 0,361 & $\mathrm{r}_{\text {hitung }}>\mathrm{r}_{\text {tabel }}$ & Valid \\
\hline
\end{tabular}

Sumber : Hasil pengolahan Data, 2019

Table 5

Uji Validitas variable Y

\begin{tabular}{|c|c|c|c|c|}
\hline Pertanyaan & $\begin{array}{c}\text { Nilai Korelasi } \\
(\mathbf{r})\end{array}$ & r-tabel & Keterangan & Kesimpulan \\
\hline 1 & 0.566 & 0,361 & $\mathrm{r}_{\text {hitung }}>\mathrm{r}_{\text {tabel }}$ & Valid \\
\hline 2 & 0.388 & 0,361 & $\mathrm{r}_{\text {hitung }}>\mathrm{r}_{\text {tabel }}$ & Valid \\
\hline 3 & 0.670 & 0,361 & $\mathrm{r}_{\text {hitung }}>\mathrm{r}_{\text {tabel }}$ & Valid \\
\hline 4 & 0.582 & 0,361 & $\mathrm{r}_{\text {hitung }}>\mathrm{r}_{\text {tabel }}$ & Valid \\
\hline 5 & 0.651 & 0,361 & $\mathrm{r}_{\text {hitung }}>\mathrm{r}_{\text {tabel }}$ & Valid \\
\hline 6 & 0.374 & 0,361 & $\mathrm{r}_{\text {hitung }}>\mathrm{r}_{\text {tabel }}$ & Valid \\
\hline 7 & 0.656 & 0,361 & $\mathrm{r}_{\text {hitung }}>\mathrm{r}_{\text {tabel }}$ & Valid \\
\hline 8 & 0.720 & 0,361 & $\mathrm{r}_{\text {hitung }}>\mathrm{r}_{\text {tabel }}$ & Valid \\
\hline 9 & 0.432 & 0,361 & $\mathrm{r}_{\text {hitung }}>\mathrm{r}_{\text {tabel }}$ & Valid \\
\hline 10 & 0.652 & 0,361 & $\mathrm{r}_{\text {hitung }}>\mathrm{r}_{\text {tabel }}$ & Valid \\
\hline
\end{tabular}

Sumber : Hasil pengolahan Data, 2019 
Pada Tabel diatas dapat diperoleh nilai korelasi semua variabel lebih besar dari 0,361. Hal ini menunjukkan bahwa semua item pertanyaan masing-masing variabel adalah valid.

\subsection{Analisis Regresi Linear Berganda}

Analisis regresi digunakan untuk menganalisis data hasil penelitian dengan maksud untuk memperoleh gambaran hubungan fungsional antara variabel bebas dengan variabel terikat hal ini dengan menggunakan analisis regresi linier berganda.

Tabel 6

Koefisien Regresi

\begin{tabular}{|c|c|c|c|c|c|c|}
\hline & \multirow[t]{2}{*}{ Model } & \multicolumn{2}{|c|}{$\begin{array}{l}\text { Unstandardized } \\
\text { Coefficients }\end{array}$} & $\begin{array}{l}\text { Standardized } \\
\text { Coefficients }\end{array}$ & \multirow[t]{2}{*}{ t. } & \multirow[t]{2}{*}{ Sig. } \\
\hline & & B & Std. Error & Beta & & \\
\hline \multirow{5}{*}{1} & (Constant) & 5.568 & 1.570 & & 3.547 & .001 \\
\hline & Kompetensi Pegawai & 279 & 101 & .301 & 2.753 & .008 \\
\hline & Etos kerja & .165 & .078 & 167 & 2.114 & .039 \\
\hline & Fasilitas kerja & .175 & .102 & .184 & 1.722 & .091 \\
\hline & Disiplin kerja & .346 & .130 & .352 & 2.664 & .010 \\
\hline
\end{tabular}

Berdasarkan Tabel 6, diperoleh koefisien regresi variabel Kompetensi Pegawai 0,279, etos kerja 0,165, Fasilitas Kerja $=0,175$, Disiplin Kerja 0,346 dengan konstanta 5,568, maka dapat dituliskan persamaan regresi sebagai berikut.

$$
\begin{gathered}
Y=5,568+0,279 X_{1}+0,165 X_{2}+0,175 X_{3}+ \\
0,346 X_{4}+1,89
\end{gathered}
$$

Persamaan di atas menunjukkan konstanta bernilai positip dan nilai koefisien regresi juga positip. Hal ini memberi gambaran bahwa perubahan rata-rata variabel Pengembangan Pegawai (Y) tergantung dari perubahan variabel Kompetensi Pegawai $\left(\mathrm{X}_{1}\right)$, Etos kerja $\left(\mathrm{X}_{2}\right)$,

Tabel 7

Uji F (Uji Simultan)

\begin{tabular}{|c|c|c|c|c|c|c|}
\hline \multicolumn{2}{|c|}{ Model } & $\begin{array}{l}\text { Sum of } \\
\text { Squares }\end{array}$ & $\mathrm{df}$ & $\begin{array}{l}\text { Mean } \\
\text { Square }\end{array}$ & $\mathrm{F}$ & Sig. \\
\hline \multirow{3}{*}{1} & Regression & 814.117 & 4 & 203.529 & 103.996 & $.000^{\mathrm{b}}$ \\
\hline & Residual & 99.811 & 51 & 1.957 & & \\
\hline & Total & 913.929 & 55 & & & \\
\hline
\end{tabular}

ANOVA

b. Predictors: (Constant), X1, X2, X3, X4

Berdasarkan tabel di atas diketahui nilai Fhitung sebesar 103,996 sedangkan nilai F-tabel (terlampir) dengan $\mathrm{dk}$ pembilang $4 \mathrm{dan} \mathrm{dk}$ penyebut 51adalah sebesar 2,56 dimana Fhitung > F tabel $(103,996>2,56)$ maka dapat disebutkan bahwa secara bersama-sama (multiple) terdapat pengaruh positif dan signifikan Kompetensi Pegawai, etos kerja,
Fasilitas Kerja $\left(\mathrm{X}_{3}\right)$. dan disiplin kerja $\left(\mathrm{X}_{4}\right)$. Artinya apabila Kompetensi Pegawai, etos kerja, Fasilitas Kerja, Disiplin Kerja ditingkatkan akan diikuti perubahan/peningkatan pengembangan pegawai. Perubahan ini merupakan peningkatan apabila bertanda positip dan penurunan atau pengurangan jika bertanda negatif. Hal ini menunjukkan bahwa ada pengaruh Kompetensi Pegawai, Fasilitas Kerja, Disiplin Kerja terhadap pengembangan pegawai.

\subsection{Uji Signifikan Simultan (Uji F)}

Fasilitas Kerja dan Disiplin Kerja terhadap pengembangan Pegawai.

\subsection{Uji Signifikan Parsial (t)}

Untuk mengetahui pengaruh variabel bebas secara parsial terhadap variabel terikat digunakan uji t, dimana dengan ketentuan : 
a. t- hitung $\leq \mathrm{t}$ - tabel (tidak ada pengaruh variabel bebas secara tersendiri terhadap variabel terikat) b. t- hitung > t- tabel (ada pengaruh variabel bebas secara tersendiri terhadap variabel terikat)

c. derajat kebebasan $(\mathrm{dk})=\mathrm{n}-4$ dan Tingkat kepercayaan $\alpha=0,05$.

Tabel 8

Uji Parsial (Uji t)

\begin{tabular}{|l|r|r|r|r|r|}
\hline \multirow{2}{*}{ Model } & \multicolumn{2}{|c|}{$\begin{array}{c}\text { Unstandardized } \\
\text { Coefficients }\end{array}$} & $\begin{array}{c}\text { Standardized } \\
\text { Coefficients }\end{array}$ & \multirow{2}{*}{ t. } & \multirow{2}{*}{ Sig. } \\
\cline { 2 - 4 } & \multicolumn{1}{|c|}{ B } & Std. Error & \multicolumn{1}{c|}{ Beta } & & \\
\hline (Constant) & 5.568 & 1.570 & & 3.547 & .001 \\
Kompetensi Pegawai & .279 & .101 & .301 & 2.753 & .008 \\
Etos kerja & .165 & .078 & .167 & 2.114 & .039 \\
Fasilitas kerja & .175 & .102 & .184 & 1.722 & .091 \\
Disiplin kerja & .346 & .130 & .352 & 2.664 & .010 \\
\hline
\end{tabular}

Berdasarkan tabel 8. di atas diperoleh

1. Nilai $t_{\text {hitung }}$ Kompetensi Pegawai $=2,753$, sedangkan t-tabel dengan dk 56 sebesar 1,67 maka thitung > t-tabel dengan demikian secara parsial ada pengaruh yang signifikan antara Kompetensi Pegawai terhadap pengembangan pegawai.

2. Nilai $t_{\text {hitung }}$ Etos Kerja $=2,132$, sedangkan ttabel dengan $\mathrm{dk} 56$ sebesar 1,67 maka $\mathrm{t}$ hitung > t tabel dengan demikian secara parsial ada pengaruh yang signifikan antara etos kerja terhadap pengembangan pegawai.

3. Nilai $t_{\text {hitung }}$ Fasilitas Kerja $=1,762$, sedangkan t-tabel dengan dk 56 sebesar 1,67 maka $\mathrm{t}$ hitung $>\mathrm{t}$ tabel dengan demikian secara parsial ada pengaruh yang signifikan antara Fasilitas Kerja terhadap pengembangan pegawai.

4. Nilai $t_{\text {hitung }}$ Disiplin Kerja $=2,664$, sedangkan t-tabel dengan dk 56 sebesar 1,67 maka $\mathrm{t}$ hitung > $\mathrm{t}$ tabel dengan demikian secara parsial ada pengaruh yang signifikan antara Disiplin Kerja terhadap pengembangan pegawai.

\subsection{Uji Determinasi (R Square)}

Tabel 9

Model Summary

\begin{tabular}{|l|r|r|r|r|}
\hline Model & R & R Square & Adjusted R Square & Std. Error of the Estimate \\
\hline 1 & $.944^{\mathrm{a}}$ & .891 & .882 & 1.39896 \\
\hline
\end{tabular}

Sumber; Pengolahan data, 2019

Berdasarkan table 9 diperoleh $\mathrm{R}^{2}=0,944$ maka $\mathrm{D}=0,89,1 \times 100 \%$ sehingga $\mathrm{D}=89,1 \%$. Akan tetapi regresi berganda lebih baik diambil nilai Adjusted R Squsre yakni 88,2\%. Dengan demikian pengaruh Kompetensi Pegawai, etos kerja, Fasilitas Kerja dan Disiplin Kerja terhadap pengembangan Pegawai sebesar $88,2 \%$. Sedangkan $11,8 \%$ lagi yang mempengaruhi pengembangan Pegawai ditentukan faktor lain yang tidak diteliti dalam penelitian ini.

\section{Kesimpulan}

Berdasarkan pada analisis dan evaluasi data di atas, maka kesimpulan dari penelitian ini adalah :
1. Ada pengaruh yang signifikan antara kompetensi terhadap pengembangan pegawai, karena menurut hasil analisis thitung > t-tabel $(2,753>1,67)$ pada $\mathrm{n}=56$ dengan taraf sifgifikansi $95 \%$.

2. Ada pengaruh yang signifikan antara etos kerja terhadap pengembangan pegawai, hasil analisis thitung $>\mathrm{t}$-tabel $(2,114>1,67)$ pada $\mathrm{n}=56$ dengan taraf sifgnifikansi $95 \%$.

3. Ada pengaruh yang signifikan antara Fasilitas kerja terhadap pengembangan pegawai, karena menurut hasil analisis thitung > t-tabel $(1,722>1,67)$ pada $\mathrm{n}=56$ dengan taraf sifgnifikan $95 \%$

4. Ada pengaruh yang signifikan antara Disiplin Kerja terhadap pengembangan 
pegawai, karena menurut hasil analisis thitung > t-tabel $(2,664>1,67)$ pada $\mathrm{n}=56$ dengan taraf sifgifikan $95 \%$.

5. Nilai F-hitung > F tabel $(103,996>2,56)$ secara bersama-sama (multiple) terdapat pengaruh positif dan signifikan kompetensi, etos kerja, Fasilitas kerja dan disiplin kerja terhadap pengembangan pegawai. Dengan demikian hipotesis yang diajukan diterima kebenarannya.

\section{DAFTAR PUSTAKA}

Alwi, Syafaruddin, (2011), Manajemen Sumber

Daya Manusia, Yogyakarta, BPFE, Grasindo.

Amin Wijaya Tunggal, (2012), Manajemen Suatu Pengantar, Cetakan Pertama, Rineka Cipta Jaya, Jakarta.Anoraga, Pandji. 2009. Manajemen Bisnis. Rineka Cipta, Jakarta.

Bertens, K. (2011). Etika. Jakarta, Gramedia

Hary Kusnadi, (2012), Manajemen Sumber Daya Manusia, Jakarta, Ghalia Indonesia.

Husein, (2009), Ensiklopedia Manajemen, Jakarta, Balai Pustaka.

Jakson, Jhom H,(2009), Manajemen Sumber Daya Manusia, Jakarta, Penerbit: Salemba Empat,

Kusnan, Ahmad. (2009). Analisis Sikap, Iklim Organisasi, Etos Kerja dan Disiplin Kerja dalam menentukan Efektifitas Kinerja Organisasi di Garnisun Tetap III Surabaya. Tesis. Universitas Airlangga,

Luthans, Fred. (2009). Perilaku Organisasi.Yogyakarta, Andi

Mar'at, (2013), Pimpinan dan Kepemimpinan, Jakarta, Ghalia Indonesia.

Mitrani, Alain, (2009), Manajemen Sumber Daya Manusia Berdasarkan Kompetensi, Jakarta, Pustaka Utama Grafiti,

Moenir, A. S, (2009): Pendekatan Manusia dan Organisasi Terhadap Pembinaan Kepegawaian, Jakarta.Gunung Agung

Poerwono, Hadi, (2012), Peningkatan Sumber Daya Manusia, Jakarta, Djambatan,

Rivai, Veithzal, (2011), Performance Appraisal, Jakarta. PT. RajaGrafindo Persada.

Ruky, Achmad, (2009), Manajemen Penggajian Dan Pengupahan Untuk Karyawan Perusahaan, Jakarta, Penerbit GramediaPustaka Utama.

Sanjaya, Wina, (2010), Kompetensi, Edisi Pertama, Cetakan I, Jakarta, Fajar Interpratama Offset
Sastrosapoetra, RA. Santoso, (2012), Manusia dan Organisasi, Jakarta : Gunung Agung

Sedarmayanti, (2012), Sumberdaya Manusia dan Produktivitas Kerja. Bandung: Ilham Jaya

Siagian, S.P,(2009): Organisasi, Kepemimpinan dan Prilaku Organisasi, Jakarta, Gunung Agung

Sinamo, Jansen. (2013). Delapan Etos Kerja Profesional: Navigator Anda Menuju Sukses.Bogor, Grafika Mardi Yuana

Soerjadi, (2012) : Pembangunan Masyarakat, Bandung, CV. Mandar Maju,

Sudjana, (2010), Metoda Statistika, Bandung. Tarsito.

Sukirno, Sadono, (2013), Pengantar Ekonomi Makro, Jakarta: LPFE-UI

Suseno, K, (2011), Manajemen Sumber Daya Manusia di Era Globalisasi, Jakarta : Bumi Aksara

Tasmara, (2012), Pengantar Studi Penelitian Kebijakan, Jakarta, Bumi Aksara

Triton, (2009), Prilaku Organisasi, Jakarta, Raja Grafindo Persada

Wetik, J. L, (2012), Penelitian dan Produktivitas, Jakarta, Erlangga.

Wijaya Tony, Cepar Menguasai SPSS Untuk Olah \& Interpretasi Data Penelitian, (2011), Yogyakarta, Cahaya Atma

Winardi, (2012), Manajemen Prilaku Organisasi, Bandung, PT. Citra Aditya, 